NASA/TM-1999-209048

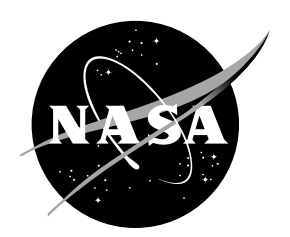

\title{
Comparison Tools for Assessing the Microgravity Environment of Orbital Missions, Carriers and Conditions
}

Richard DeLombard

Glenn Research Center, Cleveland, Ohio

Kenneth Hrovat

Tal-Cut Company, North Olmsted, Ohio

Kevin M. McPherson

Glenn Research Center, Cleveland, Ohio 
Since its founding, NASA has been dedicated to the advancement of aeronautics and space science. The NASA Scientific and Technical Information (STI) Program Office plays a key part in helping NASA maintain this important role.

The NASA STI Program Office is operated by Langley Research Center, the Lead Center for NASA's scientific and technical information. The NASA STI Program Office provides access to the NASA STI Database, the largest collection of aeronautical and space science STI in the world. The Program Office is also NASA's institutional mechanism for disseminating the results of its research and development activities. These results are published by NASA in the NASA STI Report Series, which includes the following report types:

- TECHNICAL PUBLICATION. Reports of completed research or a major significant phase of research that present the results of NASA programs and include extensive data or theoretical analysis. Includes compilations of significant scientific and technical data and information deemed to be of continuing reference value. NASA's counterpart of peerreviewed formal professional papers but has less stringent limitations on manuscript length and extent of graphic presentations.

- TECHNICAL MEMORANDUM. Scientific and technical findings that are preliminary or of specialized interest, e.g., quick release reports, working papers, and bibliographies that contain minimal annotation. Does not contain extensive analysis.

- CONTRACTOR REPORT. Scientific and technical findings by NASA-sponsored contractors and grantees.
- CONFERENCE PUBLICATION. Collected papers from scientific and technical conferences, symposia, seminars, or other meetings sponsored or cosponsored by NASA.

- SPECIAL PUBLICATION. Scientific, technical, or historical information from NASA programs, projects, and missions, often concerned with subjects having substantial public interest.

- TECHNICAL TRANSLATION. Englishlanguage translations of foreign scientific and technical material pertinent to NASA's mission.

Specialized services that complement the STI Program Office's diverse offerings include creating custom thesauri, building customized data bases, organizing and publishing research results ... even providing videos.

For more information about the NASA STI Program Office, see the following:

- Access the NASA STI Program Home Page at http://www.sti.nasa.gov

- E-mail your question via the Internet to help@sti.nasa.gov

- Fax your question to the NASA Access Help Desk at (301) 621-0134

- Telephone the NASA Access Help Desk at (301) 621-0390

- Write to:

NASA Access Help Desk

NASA Center for AeroSpace Information 7121 Standard Drive

Hanover, MD 21076 
NASA/TM-1999-209048

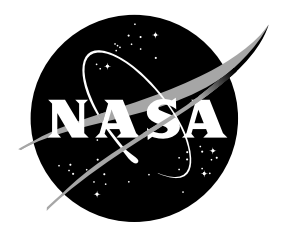

\section{Comparison Tools for Assessing the Microgravity Environment of Orbital Missions, Carriers and Conditions}

Richard DeLombard

Glenn Research Center, Cleveland, Ohio

Kenneth Hrovat

Tal-Cut Company, North Olmsted, Ohio

Kevin M. McPherson

Glenn Research Center, Cleveland, Ohio

Prepared for the 16th Instrumentation and Measurement Technology Conference sponsored by the Institute of Electrical and Electronics Engineers

Venice, Italy, May 24-26, 1999

National Aeronautics and

Space Administration

Glenn Research Center 
Available from

NASA Center for Aerospace Information 7121 Standard Drive

Hanover, MD 21076

Price Code: A03
National Technical Information Service 5285 Port Royal Road Springfield, VA 22100 Price Code: A03 


\title{
Comparison Tools for Assessing the Microgravity Environment of Orbital Missions, Carriers and Conditions
}

\author{
Richard DeLombard $^{\mathrm{a}}$, Kenneth Hrovat ${ }^{\mathrm{b}}$, and Kevin M. McPherson ${ }^{\mathrm{a}}$ \\ ${ }^{a}$ NASA Glenn Research Center, Cleveland, Ohio, U.S.A. \\ b Tal-Cut Company, North Olmsted, Ohio, U.S.A.
}

\begin{abstract}
The Principal Component Spectral Analysis and the Quasi-steady Three-dimensional Histogram techniques provide the means to describe, on a single plot, the microgravity acceleration environment of a long period of time, such as a day, week, or month. This allows a straight forward comparison of the microgravity environment between microgravity increments on the International Space Station, locations within the International Space Station, and/or different operating conditions.

Traditional data display methods (e.g. acceleration versus time), while adequate for shorter time periods, would utilize more plots for an extensive period of time, often making interpretation more difficult. These new techniques provide a single page representation of a large set of microgravity acceleration data. These techniques, in conjunction with other techniques, may be employed to derive useful information from acceleration data to characterize or compare the microgravity environment.
\end{abstract}

\section{Introduction}

The NASA Glenn Research Center (GRC) manages several projects for measuring the acceleration environment on board the NASA Orbiter missions, Russia's Mir space station, free flyers and, in the near future, the International Space Station. These data and the subsequent analyses support the needs of Principal Investigators to aid in interpreting scientific experiments on these carriers.

The GRC accelerometers for Orbiter missions are the Space Acceleration Measurement System (SAMS) [1] and the Orbital Acceleration Research Experiment (OARE) instrument [2]. In addition, one SAMS unit was installed on the Mir space station from 1994 until 1998. The SAMS measures the vibratory and transient environment from $0.01 \mathrm{~Hz}$ up to $100 \mathrm{~Hz}$ with a set of three distributed triaxial sensor heads. The OARE measures the quasi-steady accel- eration environment below about $1 \mathrm{~Hz}$ near the Orbiter's center of mass.

The data sets from these instruments are analyzed by the NASA GRC Principal Investigator Microgravity Services (PIMS) project and the results are provided to the Principal Investigators. After each mission with a SAMS and/or OARE instrument on board, the PIMS project prepares a summary report (e.g. [3]) of the mission's acceleration environment. These reports are prepared for use by principal investigators during their experimental data analysis. The PIMS project also provides real-time and near-real-time analysis of the acceleration data during missions for which SAMS and/or OARE data are available via Orbiter downlink.

A number of standard formats for data display have been developed to illustrate the acceleration data acquired from the missions. Common formats are acceleration versus time, power spectral density versus frequency, and spectrograms (power spectral density versus frequency versus time). Each of these formats is explained in [4] and [5]. The format to select depends on the quantity of data considered, the requester's needs, and the type of desired information. Analysis of extensive periods of time using these techniques results in many pages of plots.

There has been a need for a simple, integrated characterization of a mission, carrier, or time period, in order to compare with another mission, carrier, or time period. The PIMS project developed two new techniques, the Principal Component Spectral Analysis (PCSA) and the Quasi-steady Three-dimensional Histogram (QTH). The PCSA and QTH techniques are valuable tools for extracting useful information from acceleration data taken over large spans of time. As will be shown in this paper, the PCSA and QTH techniques bring both the range and median of the microgravity environment onto a single page for an entire mission or a specific time period of interest. These single pages may then be used to compare 
similar analyses of other missions, time periods or conditions.

The PCSA plot is based on the frequency distribution of the vibrational energy and is normally used for an acceleration data set containing frequencies above the lowest natural frequencies of the vehicle (e.g. SAMS data). The QTH plot is derived from the component measurements and it provides a summary of the magnitude and direction of the acceleration. The QTH is normally used for acceleration data sets with frequency content less than $0.1 \mathrm{~Hz}$ (e.g. OARE data).

Various disturbances to the laboratory environment are made evident by using PCSA and QTH plots. Vibrations of sufficient magnitude from equipment operating part time are very evident as are vibrations from equipment contributing to the background acceleration environment. A source's magnitude and/or frequency variability is also evident by the source's appearance on a PCSA plot.

\section{Principal Component Spectral Analysis}

\subsection{PCSA Methodology}

The source of microgravity acceleration data for a PCSA plot is a sampled data set produced by an accelerometer system, such as SAMS. The data set to be analyzed is first divided into successive equal-duration time intervals. The chosen duration of an interval is based upon the desired frequency resolution, where the frequency resolution is given by

$$
\Delta f=1 /\left(\Delta t_{i}\right),
$$

where $\Delta \mathrm{f}$ is the frequency resolution (in Hertz) and $\Delta \mathrm{t}_{\mathrm{i}}$ is the length of time (in seconds) in each of the intervals. The power spectral density [4] for each interval is then computed.

The next step in the PCSA processing is to determine the significant spectral peaks in each of the power spectral density plots from all of the successive time intervals. For the purpose of this discussion, a significant spectral peak (figure 1) is defined to be a power spectral density magnitude value that is a local maximum that is at least as high as any other magnitude point within a specified frequency range. For example, all of the asterisk marked values in figure 1 could be considered significant spectral peaks. The frequency range is usually specified by a number of frequency resolution intervals (a neighborhood) on either side of a datum point. Typical values for this neighborhood are $0.05-0.10 \mathrm{~Hz}$ for SAMS data.

The magnitude and frequency of the significant spectral peaks are extracted from each individual power spectral density plot and stored as intermediate results. From these sets of magnitude values versus frequency, a two-dimensional histogram is calculated by quantizing both the magnitude and frequency to desired resolutions and assigning a count for each magnitude/frequency bin. A color is then assigned based on the number (count) of points falling within each of the magnitude/frequency bins. The colors indicate the relative amount of time that the power spectral density value was a certain magnitude for each frequency being considered, as shown in figure 2 . The magnitude resolution is usually shown logarithmically with the upper and lower magnitude bounds of the bins defined by $10^{-\mathrm{N} / 20}$ $\mathrm{g}^{2} / \mathrm{Hz}$, for $\mathrm{N}=40$ to 240 . This corresponds to the upper and lower power spectral density magnitude bounds of $10^{-2}$ and $10^{-12} \mathrm{~g}^{2} / \mathrm{Hz}$.

The two-dimensional histogram calculation yields an array of the number of points falling within each magnitude/frequency bin. Therefore, the raw results of the histogram analysis are dependent on the total time period analyzed (e.g. 1 hour, or 10 days). A larger time period would be expected to result in a larger number of occurrences in any given bin. In order to counteract this time dependence, a normalization procedure is implemented by which the number of occurrences in any given bin are divided by the total number of periods analyzed for the plot. By doing this, a measure of the percentage of time is achieved by the following equation:

$$
t_{p}=\frac{p}{M} \times 100 \%,
$$

where $t_{p}$ is the percentage of time, $p$ is the number of points falling within any given bin, and $\mathrm{M}$ is the number of periods analyzed for the PCSA plot. This data set is then imaged on a semi-log plot as in figure 2. This figure illustrates a PCSA plot for the SAMS data from the STS-78 mission which had the Life and Microgravity Spacelab (LMS) as the primary payload. Features of this data plot will be discussed in the next section.

\subsection{PCSA Interpretation}

An individual set of significant spectral peak points extracted from a power spectral density plot (figure 1) indicate the upper levels of the acceleration spectrum for the time period of that particular power spectral density plot. This upper level of the acceleration spectrum is of interest to the vast majority of principal investigators for their analysis of the environment. For a complete PCSA plot, the range of the acceleration spectrum upper levels is bounded by the upper and lower edges of the color bands. Thus, with a single plot, the PCSA technique shows the range of the microgravity environment for the time period covered by the plot. 
The PIMS project has correlated features of the PCSA plots with known mission events for numerous missions. The basic interpretation of the plot's data is that the colors higher up the color bar scale (i.e. towards magenta) indicate that a magnitude/frequency combination occurred more often than that combination with a color lower on the scale. The bright band of reds/yellows/greens indicates the propensity of the microgravity environment to be in that region for much of the time included in the plot. This is illustrated in figure 2 where, for example, the tendency is for the environment below $1 \mathrm{~Hz}$ to be around $10^{-9} \mathrm{~g}^{2} / \mathrm{Hz}$.

Individual disturbances may be identified by certain characteristic shapes in a PCSA plot. The Ku-band antenna on the Orbiter dithers at a controlled $17 \mathrm{~Hz}$ rate to prevent mechanical stiction. This fixed vibration rate produces the thin vertical line at $17 \mathrm{~Hz}$ in figures 1 and 2 . The white area (representing very few histogram 'hits') below the $17 \mathrm{~Hz}$ thin vertical line in figure 2 means that the vibration at $17 \mathrm{~Hz}$ does not drop below $2 \times 10^{-6} \mathrm{~g}^{2} / \mathrm{Hz}$ for any appreciable time in the mission. The conclusion drawn from this data is that the $\mathrm{Ku}$-band antenna is operating for most, if not all of the mission. This is a normal condition for a mission of this nature where the Ku-band antenna is used for data downlink.

Vehicle and payload structural vibration mode frequencies are seen in a PCSA plot as the broad magnitude peaks in the lower frequency regions below $10 \mathrm{~Hz}$.

In figure 2 , between $8 \mathrm{~Hz}$ and $22 \mathrm{~Hz}$, the propensity of the environment has split into a higher level and a lower level. This differentiation is due to the alternating active and rest periods of the crew throughout the single shift mission. This was confirmed by creating two separate PCSA plots, one for crew active periods and one for crew rest periods.

There were two refrigerators on-board the Shuttle during STS-78 and the vibration from their motor-driven compressors may be seen around $22 \mathrm{~Hz}$. These compressors caused a very noticeable variable frequency disturbance around $22 \mathrm{~Hz}$. Since the compressors cycled on and off throughout the mission, there are histogram "hits" below the peak values, unlike the Ku-band antenna which was on for the entire mission.

\subsection{PCSA Comparison}

There have been many situations where a user has asked the PIMS project to prepare a comparison of a period of time from one mission with a period of time from either the same or a different mission. Such a comparison is not reasonable to perform by using standard power spectral density plots because the microgravity acceleration environment is so dynamic. Comparison of long-duration power spectral density plots is hindered by the non-stationary nature of the acceleration environment.

A PCSA plot allows the user to make a visual comparison between missions, carriers (e.g. the Spacelab module and the Orbiter's middeck), time periods within a mission (e.g. crew active and crew sleep) and mission conditions (e.g. refrigerators on and off).

\section{Quasi-steady Three-dimensional Histogram}

\subsection{QTH Methodology}

The source of microgravity acceleration data for a QTH plot is a sampled data set produced by a low frequency accelerometer system, such as the OARE. The OARE data for the LMS mission are shown in figure 3.

The original OARE data are acceleration measurements digitized at a rate of 10 samples per second for each of the $\mathrm{X}, \mathrm{Y}$, and $\mathrm{Z}$ axes. Prior to its use in QTH plots, the data are transformed from the OARE coordinate system to the Orbiter body coordinate system [5] and a trimmean filter is applied to the data [2].

From these sets of three-axis magnitude values, three two-dimensional histograms are formed by plotting pairs of the three-axis data points in three scatter diagrams (figure 4). These three diagrams provide front, side, and top views of the acceleration vectors in the Orbiter body axis system. The histogram is calculated by quantizing the magnitudes to a desired resolution and assigning a count for an occurrence in each bin. A color is then assigned based on the number of occurrences that fall within each bin. The scale magnitude is linear with a range of $\pm 3 \mu \mathrm{g}$.

The two-dimensional histogram calculation yields a matrix of the number of points falling within each histogram bin. Therefore, the raw results of the histogram analysis are dependent on the total time period analyzed (e.g. 1 hour, or 10 days). A larger time period would be expected to result in a larger number of coincidences in any given bin. To counteract this time dependence, a similar normalization procedure is implemented as with the PCSA.

This data set is then imaged as the three scatter plots in figure 4. The axis origin is centered on the OARE instrument sensor's location. As acceleration data, a QTH data point should be viewed as the tip of a vector with an origin at the OARE sensor. The location of the data point in the QTH then gives a relative indication of the quasi-steady acceleration vector magnitude and direction.

The OARE data from a mission may also be transformed to different locations on the Orbiter by incorporating the Orbiter state vector data [4]. These transformed data may then be used to prepare a QTH plot to indicate 
the quasi-steady conditions at an experiment location or any other position of interest.

\subsection{QTH Interpretation}

For this paper, the QTH plot for the STS-62 mission will be used to show some of the characteristics discernible with this technique. Correlation of the QTH plots with known mission events (e.g. Orbiter attitudes, water dumps) has led to the interpretation of the QTH plot characteristics relative to mission activities and vehicle equipment operation. The basic interpretation of the plot's data is that the colors higher up the color-bar scale (toward magenta) indicate that the acceleration vector fell into that bin more often than those bins with a color lower on the scale. The bright area of reds/magentas indicate the propensity of the microgravity environment to be in that region for most of the time of the data included in the plot.

The main Orbiter attitudes utilized during the microgravity portion of the STS-62 mission are described in the PIMS mission summary report [3] for STS-62. Three of the attitudes were $-\mathrm{XLV} / \mathrm{ZVV}$ (tail to Earth, cargo bay forward), $-\mathrm{XLV} /+\mathrm{ZVV}$ (tail to Earth, belly forward), and -ZLV/+YVV (cargo bay to Earth, right wing forward). Attitude-dependent acceleration vectors, such as atmospheric drag and gravity-gradient accelerations, in these attitudes produced the unique characteristics in figure 4 labelled A, B, and C, respectively. For example, the atmospheric drag component reverses the sign of the Z-axis accelerations between attitudes $\mathrm{A}$ and $\mathrm{B}$ where the Orbiter cargo bay is forward facing in attitude A and the belly is forward in attitude B.

During part of the STS-62 mission, the Orbiter operated in the -ZLV/+YVV attitude in an elliptical orbit with altitudes of 105 nautical miles (perigee) and 138 nautical miles (apogee). The contribution of this flight mode is the linear characteristic labelled D in figure 4. This is due to the increased atmospheric drag at the lower altitudes which increased the acceleration levels in the axis directed into the velocity vector (the $\mathrm{Y}_{\mathrm{b}}$ axis in this case).

The general range of microgravity environment conditions for the time of the data included in a QTH plot is bounded by the extent of the colored areas in the plot. Due to the processing technique used, there may be individual points outside the colored areas, though.

\subsection{QTH Comparison}

There have been many situations where a user has asked the PIMS project to prepare a comparison of the quasi-steady conditions for a long period of time in an Orbiter mission with another period of time in the same mission or for a comparison between missions. Such comparisons using plots of acceleration versus time are not adequate because the microgravity quasi-steady acceleration levels slowly change over time. The overall conditions are not readily apparent. The QTH plot allows the user to make a visual comparison between missions, carriers, time periods of a given mission, and conditions (i.e. attitudes, crew activity, etc.) by showing long-duration changes in the quasi-steady acceleration environment in a single plot.

\section{Application to the International Space Station}

These techniques for large quantities of data will be particularly useful for the interpretation of the vast quantity of microgravity environment data resulting from operations on the International Space Station. With microgravity increments lasting a minimum of thirty days, the microgravity environment of an increment will be summarized well by PCSA and QTH plots.

The other techniques will continue to be used but for long-term evaluation and comparison of the International Space Station environment, the PCSA and QTH are valuable.

\section{Conclusions}

The PCSA and QTH plots provide tools with which to compare different sets of microgravity acceleration data. These techniques, as well as others, may be employed in the analysis of acceleration data from microgravity science missions in order to derive useful information in support of the microgravity science experiments.

\section{References}

[1] DeLombard, R. and Finley, B.D., "Space Acceleration Measurement System Description and Operation on the First Spacelab Life Sciences Mission,” NASA TM-105301, 1991.

[2] Blanchard, R. C.; Hendrix, M. K.; Fox, J. C.; Thomas, D. J.; and Nicholson, J. Y., "Orbital Acceleration Research Experiment," J. of Spacecraft and Rockets, Vol. 24, No. 6, 1987.

[3] Rogers, M. J. B. and DeLombard, R., "Summary Report of Mission Acceleration Measurements for STS-62," NASA TM-106773, 1994.

[4] Rogers, M. J. B., Hrovat, K., McPherson, K., Moskowitz, M. E., and Reckart, T., "Accelerometer Data Analysis and Presentation Techniques, NASA TM-113173, September 1997.

[5] DeLombard, R., "Compendium of Information for Interpreting the Microgravity Environment of the Orbiter Spacecraft," NASA TM-107032, 1996. 


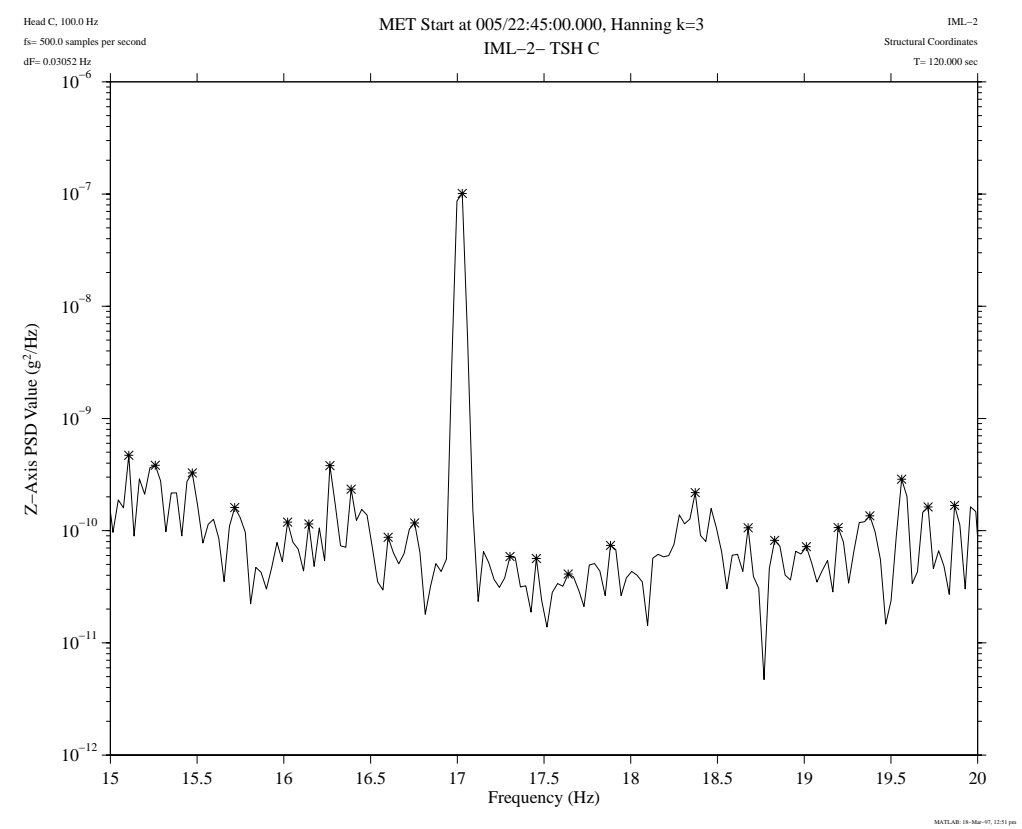

Figure 1: Extraction of spectral peaks from a portion of a typical Power Spectral Density plot



Figure 2: Principal Component Spectral Analysis plot of SAMS data for entire STS-78 mission with LMS payload 

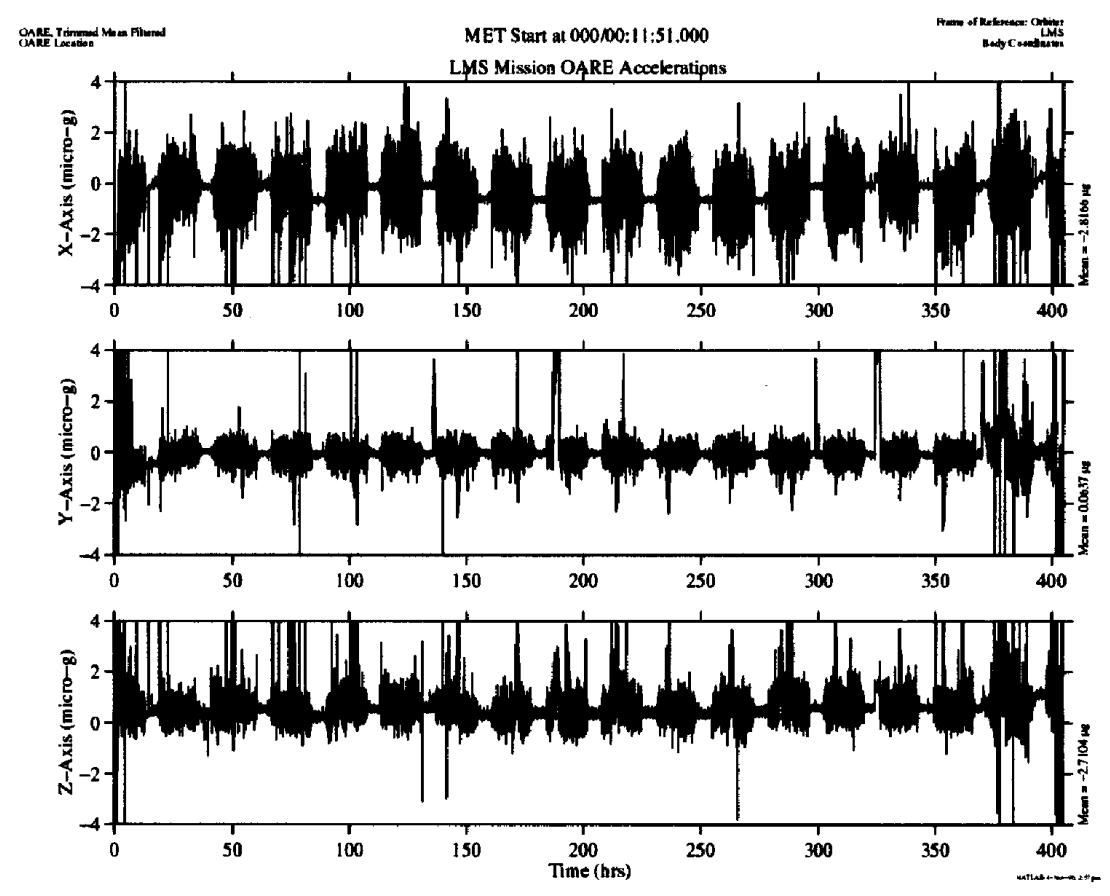

Figure 3: OARE sampled data set in acceleration vs. time for entire STS-78 mission with LMS payload

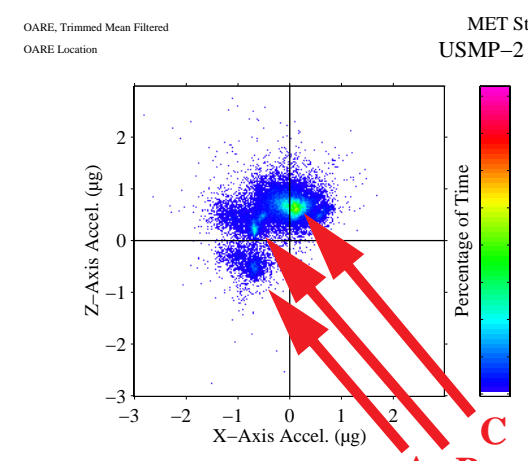

A B

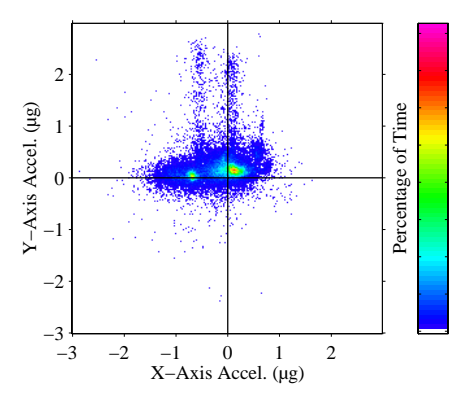

MET Start at 000/00:12:16.920

$$
\text { TS-62) Mission Plot }
$$

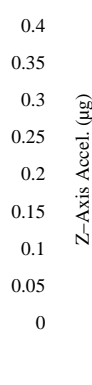

0.4

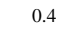

0.35

0.3
0.25

$0.2 \quad$ Frame of Reference: Orbiter

0.15

$0.1 \quad \mathrm{~T}=333.4$ hours

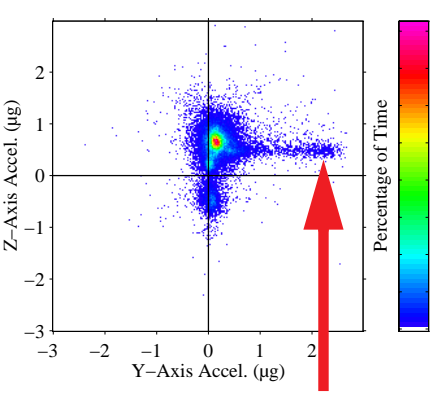

D
Body Coordinates

Figure 4: Quasi-steady Three-dimensional Histogram plot of OARE data for entire STS-62 mission with USMP-2 payload 
Public reporting burden for this collection of information is estimated to average 1 hour per response, including the time for reviewing instructions, searching existing data sources, gathering and maintaining the data needed, and completing and reviewing the collection of information. Send comments regarding this burden estimate or any other aspect of this collection of information, including suggestions for reducing this burden, to Washington Headquarters Services, Directorate for Information Operations and Reports, 1215 Jefferson Davis Highway, Suite 1204, Arlington, VA 22202-4302, and to the Office of Management and Budget, Paperwork Reduction Project (0704-0188), Washington, DC 20503.

\begin{tabular}{|l|l|l}
\hline 1. AGENCY USE ONLY (Leave blank) & $\begin{array}{c}\text { 2. REPORT DATE } \\
\text { March } 1999\end{array}$ & $\begin{array}{c}\text { 3. REPORT TYPE AND DATES COVERED } \\
\text { Technical Memorand }\end{array}$
\end{tabular}

\section{TITLE AND SUBTITLE}

5. FUNDING NUMBERS

Comparison Tools for Assessing the Microgravity Environment of Orbital Missions, Carriers and Conditions

6. AUTHOR(S)

Richard DeLombard, Kenneth Hrovat, and Kevin M. McPherson

WU-398-95-0A-00

\section{PERFORMING ORGANIZATION NAME(S) AND ADDRESS(ES)}

National Aeronautics and Space Administration

Glenn Research Center at Lewis Field

Cleveland, Ohio 44135-3191

8. PERFORMING ORGANIZATION REPORT NUMBER

E-11580

\section{SPONSORING/MONITORING AGENCY NAME(S) AND ADDRESS(ES)}

National Aeronautics and Space Administration

Washington, DC 20546-0001

10. SPONSORING/MONITORING AGENCY REPORT NUMBER

NASA TM-1999-209048

\section{SUPPLEMENTARY NOTES}

Richard DeLombard, NASA Glenn Research Center; Kenneth Hrovat, Tal-Cut Company, 24831 Lorain Road, Suite 203, North Olmsted, OH 44070 (work funded under NAS3-27254); and Kevin M. McPherson, NASA Glenn Research Center. Prepared for the 16th Instrumentation and Measurement Technology Conference, sponsored by the Institute of Electrical and Electronics Engineers, Venice, Italy, May 24-26, 1999. Responsible person, Richard DeLombard, organization code 6727, (216) 433-5285.

12a. DISTRIBUTION/AVAILABILITY STATEMENT

12b. DISTRIBUTION CODE

Unclassified - Unlimited

Subject Categories: 19, 35, and 18

Distribution: Nonstandard

This publication is available from the NASA Center for AeroSpace Information, (301) 621-0390.

13. ABSTRACT (Maximum 200 words)

The Principal Component Spectral Analysis and the Quasi-steady Three-dimensional Histogram techniques provide the means to describe, on a single plot, the microgravity acceleration environment of a long period of time, such as a day, week, or month. This allows a straight forward comparison of the microgravity environment between microgravity increments on the International Space Station, locations within the International Space Station, and/or different operating conditions. Traditional data display methods (e.g. acceleration versus time), while adequate for shorter time periods, would utilize more plots for an extensive period of time, often making interpretation more difficult. These new techniques provide a single page representation of a large set of microgravity acceleration data. These techniques, in conjunction with other techniques, may be employed to derive useful information from acceleration data to characterize or compare the microgravity environment.

14. SUBJECT TERMS

Acceleration; Microgravity; International Space Station; Instrumentation; Measurement

\begin{tabular}{|c|c|c|}
\hline $\begin{array}{c}\text { 17. SECURITY CLASSIFICATION } \\
\text { OF REPORT } \\
\text { Unclassified }\end{array}$ & $\begin{array}{c}\text { 18. SECURITY CLASSIFICATION } \\
\text { OF THIS PAGE } \\
\text { Unclassified }\end{array}$ & $\begin{array}{c}\text { 19. SECURITY CLASSIFICATION } \\
\text { OF ABSTRACT } \\
\text { Unclassified }\end{array}$ \\
\hline
\end{tabular}

NSN 7540-01-280-5500

Standard Form 298 (Rev. 2-89) 